\title{
Uma igreja sinodal e "em saída" na Amazônia: Os maiores desafios apontados por bispos do Brasil
}

\author{
A synodal church and "which goes forth" in the Amazon: \\ the biggest challenges pointed by Brazilian bishops
}

JOACHIM ANDRADE ${ }^{a}$

ESTÊVÃO RASCHIETTI ${ }^{b}$

\section{Resumo}

Dentre os inúmeros desafios que emergiram no processo de preparação do Sínodo da Amazônia, bispos sinodais do Brasil selecionaram sete mais urgentes. Eles são fruto da escuta de dos povos originários, ribeirinhos e quilombolas, nas florestas ou nas cidades, apontando para novos caminhos para a Igreja e para uma ecologia integral. Para o aprofundamento da reflexão dos bispos sinodais a respeito, cada desafio ganhou um tratamento teológico-pastoral, na perspectiva das diretrizes do documento de preparação do evento. A preocupação dos bispos é com a vida dos povos na região e com a missão da Igreja naquele contexto. Além do cuidado e defesa da ecologia, há a afirmação da necessidade de uma Igreja com rosto amazônico, que passa pela inculturação da fé, o acesso das comunidades eclesiais aos sacramentos e a efetiva participação das mulheres, assim como pela formação dos agentes de pastoral e o aprimoramento das comunicações na região.

Palavras-chave: Amazônia. Sínodo. Bispos. Missão. Ecologia.

\footnotetext{
a Pontifícia Universidade Católica do Paraná (PUCPR), Curitiba. Doutor em Ciências da Religião, e-mail: joachimandrade@terra.com.br

b Centro Cultural Conforti (CCC), Curitiba, Brasil. Mestre em Teologia, e-mail: rasquio@yahoo.com.br
} 


\section{Abstract}

Among the innumerable challenges that emerged in the process of preparation for the Synod of Amazonia, synodal bishops of Brazil selected seven more urgent ones. They are the result of listening to the native peoples, ribeirinhos and quilombolas, in forests or cities, pointing to new paths for the Church and for an integral ecology. In order to deepen the reflection of the synodal bishops, each challenge gained a theological-pastoral treatment, in the perspective of the guidelines of the document prepared for the event. The concern of the bishops is with the life of the peoples in the region and with the mission of the Church in that context. In addition to the care and defense of ecology, there is also the affirmation of the need for a Church with an Amazonian face, which involves the inculturation of the faith, the access of the ecclesial communities to the sacraments, the effective participation of women, as well as the formation of pastoral and the enhancement of communications in the region.

Keywords: Amazon. Synod. Bishops. Mission. Ecology.

Por expressa vontade do Papa Francisco, o Sínodo da Amazônia foi cuidadosamente preparado por um longo período de escuta dos povos da região, que abarca terras de nove países (PALOSCHI, 2019, p. 17-19). E começou com ele mesmo, por uma visita pastoral a Porto Maldonado, no Peru, no dia 19 de janeiro de 2018. Ao todo, foram 87 eventos de escuta, entre assembleias, simpósios e seminários, coordenados pela Rede Panamazônica (REPAM), presidida pelo Cardeal Dom Claudio Humes, cuja comissão conta também com o Cardeal Pedro Barreto, Arcebispo Metropolitano de Huancayo, Peru. As contribuições, recolhidas e sistematizadas em relatório, serviram de base para outros eventos de reflexão e aprofundamento das questões levantadas, assim como da redação dos Lineamenta e do Instrumentum Laboris do Sínodo.

No Brasil, um grupo de Bispos da região amazônica, a partir do relatório de escuta do processo sinodal, selecionou sete desafios, que segundo eles mereceriam ser estudados e aprofundados pelos bispos brasileiros que participariam do Sínodo. Foram indicados: 1 . Defesa da vida, dos direitos e dos territórios na Amazônia, terra em disputa; 2. Participação e protagonismo das mulheres na Igreja; 3. Uma Igreja com rosto indígena e ribeirinho; 4. Criação de novos ministérios, acesso ao ministério ordenado, formação e organização dos ministérios; 5. Os contextos urbanos na Amazônia: desafios e urgências para 
uma Igreja em saída; 6 . Formação teológico-política do clero e dos leigos/as na Amazônia; 7. A comunicação a partir da Amazônia.

Foi Dom Adriano Ciocca, bispo da Prelazia de São Félix do Araguaia, juntamente com o CESEP (Centro Ecumênico de Serviços à Evangelização e Educação Popular), quem tomou a iniciativa de reunir um grupo de Bispos do Brasil para se prepararem ao Sínodo, a partir da reflexão e aprofundamento dos sete desafios selecionados, assim como do estudo do Instrumentum Laboris. A redação de um texto abordando os sete desafios selecionados, a pedido do Pe. Oscar Beozzo, que atua junto ao CESEP, foi do Projeto de Missiologia integrado ao Programa de Pós-Graduação em Teologia da PUC do Paraná, em Curitiba. Solicitou-se uma fundamentação teológico-pastoral dos desafios selecionados, em uma quinzena de páginas. O trabalho foi elaborado por três teólogos ligados ao Projeto (Joachim Andrade, Estêvão Raschietti, Agenor Brighenti). Posteriormente, 0 texto recebeu sugestões de complementações e ajustes por parte de pessoas e entidades ligadas ao processo de preparação do Sínodo.

O texto, aqui partilhado, serviu de base de estudo aos bispos sinodais brasileiros em dois eventos: o primeiro foi uma reunião realizada em Aparecida no mês de maio, por ocasião da Assembleia Geral da CBBB, e o segundo foi um seminário que teve lugar em Brasília, no Centro Cultural Missionário, no mês de julho. O objetivo nosso, aqui, ao publicar o texto por nós redigido, é partilhar algo da riqueza coletada no processo de escuta em preparação do Sínodo.

\section{Desafios oriundos de um contexto particular}

Não há como desembarcar na Amazônia sem deixar-se surpreender pelos ecos deste mundo, mais paraíso que "inferno verde", mas já ostensivamente marcado pelo pecado da cobiça, respaldado em uma economia de rapinagem, que ameaça a vida dos povos da floresta e das zonas urbanas, a biodiversidade, os ecossistemas (Lineamenta 3).

Os gritos que outrora ecoavam na floresta, ordinariamente de festa e alegria, hoje são de apreensão e dor, pelo avanço da exploração da madeira, das queimadas, das pastagens e da pecuária, da soja e da cana, das 
mineradoras, dos garimpos e dos grileiros, dos "corredores" de exportação, com estadas, ferrovias e barragens para a produção de energia elétrica e criação de hidrovias. A cobiça mercantilista e suicida chegou ao sacrilégio de dizimar povos inteiros e de silenciar vozes proféticas - no Brasil, as do Pe. Rodolfo Lunkenbein SVD e de Simão Bororo, do Pe. Penido Burnier SJ, de Chico Mendes, Pe. Ezequiel Ramin MCC, Pe. Josimo Tavares, Ir. Dorothy Stang INDeeN, entre tantos outros e outras. A Igreja está presente há quatro séculos nesta região marcando sua presença em modalidades diferentes. Os modelos que foram utilizados pela Igreja na evangelização e no desenvolvimento da pastoral se encontram ultrapassados, por isso há necessidade de uma conversão estrutural e também dos missionários que atuam na região.

Para responder a estes desafios, o Sínodo para a Região Amazônica se propõe a abrir novos caminhos para a Igreja, para que siga tornando presente, de modo profético o Reino de Deus, em seu contexto e também contribua mais para uma ecologia integral. O Papa Francisco desafia a Igreja nessa região a ter um rosto amazônico (ROCA ALCAZAR, 2019, p. 55-67). Ora, um rosto próprio para a Igreja na Amazônia é um grito dos cristãos da floresta e das zonas urbanas a ser ouvido pelos bispos que estarão no Sínodo, pois teologicamente é um direito e, pastoralmente, é um dever porquanto é condição para uma ação pastoral encarnada. Para isso, estão implicadas duas questões de fundo: a necessidade da configuração das Igrejas Locais como Igrejas autóctones e a superação da mentalidade colonial pela inculturação da fé.

A legitimidade de uma Igreja autóctone remete a uma eclesialidade pluriforme, que o Vaticano II resgatou com sua "volta às fontes" (ad rimini fontes $)^{1}$ bíblicas e patrísticas. Nos primórdios do movimento de Jesus, as "Igrejas-filhas" iam nascendo de "Igrejas-mãe", diferentes, mas sem se excomungarem. Encarnando o Reino de Deus, do qual elas são seu sacramento em seu contexto particular, as diferenças entre as Igrejas, longe de ser um perigo à unidade, atestavam o exercício de uma unidade de diversidades. A Igreja é "Igreja de Igrejas" Locais (Cf. TILLARD, 1987), unidade presidida pela

\footnotetext{
${ }^{1}$ Expressão cunhada pela Igreja no século IX, inconformada pela reforma litúrgica levada a cabo pelo imperador, introduzindo elementos da cultura e da religião tradicional germânica, em dissonância com as fontes bíblicas e patrísticas.
} 
Igreja de Roma. Sua catolicidade ou universalidade está presente em cada Igreja Local, pelo fato de ter o mesmo, por inteiro, em comum com as demais (LEGRAND, 1993, p. 145s). No contexto atual, a configuração de Igrejas autóctones exige uma "sã descentralização" (Papa Francisco) da Igreja de Roma, particularmente da Cúria romana.

Uma Igreja autóctone, além de nos remeter, teologicamente, a uma eclesialidade pluriforme, pastoralmente nos remete à necessidade da inculturação da fé, condição para plasmar um rosto próprio, a partir das características e necessidades de seu próprio contexto. Da mesma forma que "o Verbo ao encarnar-se se fez cultura" (Bento XVI, Discurso Inaugural: DAp), a Igreja também é fator cultural. Em seu itinerário, por séculos, a adoção de uma eclesialidade pluriforme configurou uma Igreja pluricultural (Cf. AMERINDIA, 2019, p. 77-82). Entretanto, na medida em que a centralização foi transformando a unidade na diversidade reinante por séculos, em uniformidade a um centro autorreferencial a ser reproduzido nas periferias, no Ocidente, uma Igreja latina marcadamente monocultural se impôs como modelo de Igreja universal. A renovação do Vaticano II, ao conceber a universalidade desde as particularidades, fez da inculturação da fé um imperativo pastoral (Cf. BRIGHENTI, 1998, p. 10-23; FRANÇA MIRANDA, 2001, p. 15-33). Trata-se da encarnação da mensagem e dos mensageiros, da Igreja como um todo, incluídas suas estruturas, em um contexto particular (Cf. SCATENA, 2007; SOBRINO, 1985, p. 105-134; GUTIÉRREZ, 1987, p. 213-237).

Para isso, a Igreja na Amazônia precisa trilhar novos caminhos, que passam por uma Igreja com rosto amazônico. Um rosto a ser plasmado pela configuração de uma Igreja toda ela ministerial, pela efetiva participação e protagonismo das mulheres na Igreja e na sociedade. Também por uma pastoral urbana que leve a novas formas de presença da Igreja nas cidades e por um programa consistente de formação teológico-política do clero e dos leigos e leigas. Sem esquecer da comunicação desde a Amazônia, que reduza distâncias entre as comunidades eclesiais, seja pela multiplicação de meios de comunicação social, seja pela descentralização da vida pastoral por redes de pequenas comunidades eclesiais. 


\section{Sete desafios que interpelam e urgem respostas}

\section{$1^{\circ}$ Desafio: Amazônia, berço de vida abundante e ameaçada}

É de consenso geral que Amazônia é um lugar do equilíbrio do ecossistema. O clima quente e úmido é o maior responsável pela presença e distribuição de vegetação na região, sobretudo suas condições de drenagem e disponibilidade de nutrientes, que assumem maior importância na grande diversidade de formações vegetais. A floresta Amazônica é um dos mais complexos e diversificados biomas que existem sobre a face da Terra ${ }^{2}$. Entendemos por bioma um conjunto organizado de todas as formas de vida humana, vegetal e animal que cobre determinada região de forma contínua, em condições geoclimáticas parecidas, o que acaba formando uma diversidade biológica muito própria (Campanha da Fraternidade 2007: cf. NANDI, 2015). Na Amazônia, esse berço de vida abundante está ameaçado.

Toda região pode ser analisada a partir de dois focos distintos: situação ambiental e situação humana. Na questão ambiental, observamos que todo o ecossistema está ameaçado devido ao maltrato do meio ambiente. O controle do desmatamento tem importância por ser responsável por uma série de dinâmicas naturais, como regulação climática global e local, a preservação da biodiversidade e a relação com sistemas hídricos. O processo de desmatamento da Amazônia não ocorreu de forma linear, mas se deu com maior intensidade em locais distintos. O desmatamento ocorrido com maior incidência está associado a fatores variados como crescimento populacional, migrações, economia capitalista de mercado, urbanização e industrialização, além de causas culturais como o modo de vida familiar e questões políticas como os direitos de propriedade (ARAUJO; TAVEIRA; FOGAÇA, 2016).

A situação ambiental nos conduz à situação humana que é mais trágica, dado que os nativos estão ameaçados, migrando cada vez mais para os grandes centros urbanos, o que promove seu desenraizamento. As relações entre urbanização e vida no campo diferem, tanto espacial quanto

\footnotetext{
${ }^{2}$ Fonte: Almanaque Abril, 2002.
} 
temporalmente, nas variadas regiões do mundo e, especificamente, na região Amazônica. O inchaço e a aglomeração nos grandes centros geram conflitos de ordem local, tais como ocupações irregulares, próximas aos igarapés ou rios, impactando diretamente o ambiente. Como aponta o documento 105 da CNBB, "pela nossa realidade corpórea, Deus uniu-nos tão estreitamente ao mundo que nos rodeia, que a desertificação do solo é como uma doença para cada um e podemos lamentar a extinção de uma espécie como se fosse uma mutilação" (272). Para contextualizar, devemos ressaltar que as relações entre população e meio ambiente apresentam características bem delimitadas. Existem questionamentos e apelos em relação à ecologia integral - "o ambiente situa-se na lógica da recepção. É um empréstimo que cada geração recebe e deve transmitir à geração seguinte" (Laudato Si' 159).

O cuidado com a ecologia integral da Amazônia possui perspectiva ampla que podemos apontar a partir dos dois focos da missão: ad extra e ad intra. No contexto da missão ad extra, a Igreja faz apelo de que "somos nós os primeiros interessados em deixar um planeta habitável para a humanidade que nos vai suceder. Trata-se de um drama para nós mesmos, porque isto chama em causa o significado da nossa passagem por esta terra" (Laudato Si' 160). A questão é estabelecer o equilíbrio entre o direito de existir e o direito à alimentação. Atendendo ao grito da terra e à crise civilizatória que ameaça seriamente a integridade da vida do planeta, torna-se necessária uma ação inspirada na ecologia integral da Laudato Si', que faz uma radiografia da questão ecológica na atualidade e toma a defesa em especial das populações menos favorecidas do ponto de vista econômico, além da preocupação com a ecologia integral. O Papa Francisco lamenta que a comunidade internacional tem feito pouco progresso na proteção da biodiversidade, para estancar a desertificação, simplesmente por "falta de vontade política”. Os acordos feitos foram "mal implementados". Acordos internacionais, com a aplicação de normas reguladoras globais, são necessários, para "impor obrigações e evitar ações inaceitáveis".

Em relação à atitude ad intra, a Igreja está chamada a oferecer modelos alternativos de vida, baseados em uma abordagem do ser humano no seu relacionamento com Deus, como uma criatura que anseia pela vida eterna, vivendo em fraternidade e amor com o outro. Chegou a hora de se pensar na 
Amazônia a partir da Amazônia, com as novas formas de conceber "território e ambiente, propriedade e produção". Para isso, faz-se necessária uma conversão radical interna estrutural, estimulando a ampliação dos ministérios que possam atender o povo de Deus em todas as dimensões.

\section{$2^{\circ}$ Desafio: Uma Igreja com rosto indígena, ribeirinho e quilombola}

Uma Igreja autóctone, com rosto próprio, é uma busca da Igreja no continente, que vem de longe. Em Medellín, com sua "recepção criativa" do Vaticano II, a Igreja na América Latina deixou de ser uma "Igreja-reflexo" ou caixa de ressonância de uma suposta "Igreja universal”, para constituir-se numa fonte inspiradora e programática para as Igrejas Locais do subcontinente (SOBRINO, 1985, p. 105-134). A realização de cinco Conferências Gerais é a atestação do esforço de afirmação de sua fisionomia e de determinação na busca de efetivação de Igrejas autóctones (Cf. LUNEAU; LADRIÈRE, 1987. O mesmo se pode dizer com relação às Conferências Episcopais Nacionais, a seu importante papel desempenhado no processo de recepção do Concílio Vaticano II nas Igrejas Locais.

Historicamente, durante o período de cristandade, o cristianismo latino manteve-se como uma experiência de fé marcadamente monocultural, estruturado a partir da matriz católico-romana. Ainda no século XVI, com a conquista do novo mundo, as missões continuariam desconhecendo as diferenças culturais e confundindo evangelização com a implantação da Igreja configurada nos moldes da cultura ocidental. Em lugar de encarnar a fé na cultura, o missionário implanta uma versão de cristianismo, plasmada segundo os parâmetros de sua própria cultura. A Igreja na Amazônia guarda ainda muito dos efeitos de sua história e da história da colonização.

Hoje temos consciência de que uma Igreja com rosto próprio é uma Igreja encarnada em seu contexto concreto, fruto de um processo de proposição e acolhimento da fé, no seio do qual o sujeito é quem recebe o Evangelho e não quem o leva. Em nossas terras, o cristianismo foi implantado mais pela força do que pela persuasão. Os conquistadores que aqui desembarcaram se acreditavam investidos de uma missão, que consistia na “expansão do império e da fé” (PALOSCHI, 2019, p. 19-23). O cristianismo que 
chegou ao Continente foi uma mescla de mercado e salvação, de raízes colonaisi . Darcy Ribeiro fala de um projeto "mercantil-salvacionista", expresso no propósito de se "dilatar a fé e o império". Mundos completamente diferentes começaram a tecer laços de interação e intercâmbio, mas também de subordinação política, exploração econômica e de dominação religiosa e cultural (Cf. BEOZZO, 2005, p. 86-87).

Os aborígines da América habitavam nas planícies, florestas, em pequenas aldeias, mas também em grandes cidades, mais populosas até do que as maiores cidades da península ibérica ou da Europa, como Tenochtitlán no império azteca ou Cuzco no império incaico (Cf. BEOZZO, 2005, p. 89)3. E expressavam-se em mais de dois mil idiomas, grande parte deles hoje desaparecidos, e haviam tecido secularmente suas próprias culturas, seus mitos e religiões. Entretanto, esses mesmos aborígines, construtores de grandes civilizações como as maias, azteca, inca e guaranitica, entre tantas outras, foram humilhados em sua própria cultura, dignidade e até mesmo em sua humanidade, sendo assim justificada sua escravidão, de boa-fé ou por vil cobiça4.

Neste mesmo contexto e dentro deste mesmo paradigma, aqui aportaram os negros, arrancados de suas terras, famílias, culturas e religiões em solo africano e feitos escravos no novo mundo (Cf. APARECIDO DA SILVA, 2005, p. 183-197). Estes estiveram submetidos a quatro séculos de escravidão, situação que as leis abolicionistas repararam na teoria, mas foram ineficazes na prática, razão pela qual os negros, ainda hoje, figuram entre os mais pobres entre os pobres. Dados oficiosos dão conta que, aproximadamente, onze milhões e meio de escravos foram distribuídos nas Américas do Norte, Central, Caraíbas e América do Sul e nas ilhas do Caribe, 40\% dos quais aportou no Brasil. Remanescentes desta epopeia-tragédia são as muitas comunidades quilombolas, presentes também na região amazônica, o perfil da maioria da população brasileira que se reconhece como afro-descendente e a

\footnotetext{
${ }^{3}$ Segundo a mesma fonte, hoje no Brasil, apesar de tudo, elas totalizam 130 idiomas diferentes, entre quase 400 mil indígenas, aproximadamente, que somavam 250 mil até há pouco tempo.

${ }^{4}$ Segundo fonte supra-citada de O. Beozzo, na época da conquista, o império inca contava com 15 milhões de habitantes, o império asteca, 20 milhões, ao lado dos três milhões e meio de espanhóis, dos três milhões de ingleses e de um milhão de portugueses. Tenochtitlán, capital asteca, tinha 300 mil habitantes, ao lado dos 80 mil de Sevilha e dos 100 mil de Lisboa.
} 
onipresença da herança africana no panorama cultural e religioso do país (APARECIDO DA SILVA, 2005, p. 188-189).

Politicamente, terminada a colonização, veio o neocolonialismo, que com outros mecanismos prolongou o doloroso processo de exclusão (Cf. BRIGHENTI, 2002). Com relação à Igreja, seria preciso esperar pela renovação do Vaticano II, para mudar o paradigma da missão. Para o Concílio, evangelizar não é implantar a Igreja, mas encarnar o Evangelho na vida de pessoas circunscritas a um contexto cultural particular. Na medida em que a Igreja toda, a Igreja católica, está presente em cada Igreja Local, é na particularidade que a universalidade se faz presente. E como a Igreja é uma "Igreja de Igrejas" (TILLARD, 1987, p. 305) Locais, a universalidade das particularidades leva, necessariamente, a um cristianismo pluricultural. Segundo o Concílio, para encarnar o Evangelho no contexto de uma Igreja Local, não se trata de suprimir sua cultura, ao contrário, é preciso "conhecê-la, restaurá-la, conservá-la e desenvolvê-la segundo as novas condições e, finalmente, aperfeiçoá-la em Cristo, para que a fé e a nova Igreja não sejam estranhas na sociedade em que se inserem, mas que comece a penetrá-la e a transformá-la" (AG 21). Em consequência, a evangelização de um povo não consiste em incorporá-lo à Igreja, mas em levar a Igreja a se encarnar em sua vida. Com isso, a Igreja que nasce é sempre culturalmente nova e, por ser católica, isto é, por encarnar a universalidade na particularidade, é sempre pluricultural. Entre "incorporar" as pessoas à Igreja e "encarnar" a Igreja nas culturas, há uma diferença de paradigma, com implicações pastorais concretas.

Nos últimos tempos, graças à renovação do Vaticano II e sua "recepção criativa" levada a cabo pela Igreja na América Latina e no Caribe, tornamo-nos mais conscientes da necessidade de romper com essa lógica de violência, presente tanto nos processos pastorais como na reflexão teológica. Esforços sinceros na tessitura de um rosto próprio e tentativas de superação da lógica colonialista têm marcado esta nova trajetória, tal como atestam: as comunidades eclesiais de base, que esboçaram um rosto autóctone de Igreja; a leitura popular da Bíblia, que faz de quem recebe a mensagem o sujeito de sua interpretação e encarnação da mensagem em seu próprio meio; uma Igreja pobre e dos pobres, condição para uma Igreja de todos e testemunha do Evangelho; a inserção profética e transformadora dos cristãos na sociedade 
autônoma e pluralista, como forma de tornar presente o Reino de Deus na concretude da história; enfim, a teologia latino-americana e a teologia índia, uma reflexão da práxis da fé em perspectiva libertadora, na pluralidade dos sujeitos e de seus contextos de exclusão — os pobres em geral e, em particular, os indígenas, os negros e as mulheres (Cf. BRIGHENTI, 2012, p. 375-398; KELLER, 2017, p. 5-43; (ADAVID, 2005, p. 331-374).

Uma Igreja encarnada na Amazônia implica continuar, entre outras tarefas: fazer chegar a Palavra de Deus na língua de seus povos e situá-la no seio de pequenas comunidades de cunho doméstico; acolher símbolos das culturas nativas compatíveis com o Evangelho na celebração dos ritos cristãos e as expressões musicais locais no canto litúrgico; multiplicar o número dos celebradores da Palavra, dos catequistas e demais ministérios, nas comunidades eclesiais, em especial naquelas que não têm a celebração dominical da Eucaristia (Lineamenta 12); intensificar as ações pastorais de promoção humana como expressão de uma evangelização integral; etc. Outras frentes, entretanto, precisam ser abertas como: acolher e apoiar as teologias índia, afro-americana, feminista e a ecoteologia, enquanto suporte na configuração de uma Igreja com rosto próprio; criar novos ministérios, em especial para leigos e leigas, sobretudo para fora da Igreja, na defesa e promoção da vida, e de uma ecologia integral; formar um clero próprio, com rosto amazônico (FERREIRA, 2019, p. 24), segundo o perfil das culturas locais (PALOSCHI, 2019, p. 21); superar estruturas e modos de organização da Igreja que não convergem com a sinodalidade eclesial, como o clericalismo, o paroquialismo, o universalismo de movimentos eclesiais e o isolamento de certas Igrejas Locais; assegurar a celebração da eucaristia dominical nas comunidades eclesiais (Lineamenta 9), pela ordenação de presbíteros casados (FERREIRA, 2019, p. 28-29; cf. LOBINGER, 2007); discernir a oportunidade de ordenação de mulheres ao diaconato, assim como a criação de outros ministérios próprios, segundo as necessidades da Igreja Local (Lineamenta $13)^{5}$, etc.

\footnotetext{
${ }^{5} \mathrm{O}$ Instrumentum Laboris do Sínodo da Amazônia não entra na questão da ordenação de mulheres, ainda que se esteja fazendo uma pesquisa histórica oficial sobre a existência do diaconato feminino na tradição da Igreja. Para muitos bispos da Amazônia, dado que as 


\section{$3^{\circ}$ Desafio: Uma Igreja toda ela ministerial}

Para responder aos desafios pastorais oriundos da região amazônica, é urgente a promoção de uma Igreja toda ela ministerial, tal como têm proposto o Concílio Vaticano II e as Conferências Gerais dos Bispos da América Latina e Caribe. Para Aparecida, o clericalismo, o autoritarismo, a minoridade do laicato, a discriminação das mulheres e a falta de corresponsabilidade entre todos os batizados na Igreja, são os grandes obstáculos para levar adiante a renovação proposta pelo Vaticano II.

Daí a necessidade, para uma Igreja toda ela ministerial, de duas mudanças básicas:

a) Passar do binômio clero-leigos a comunidade-ministérios. Para o Vaticano II, não existem duas classes de cristãos - clero-leigos - mas uma única condição, a dos batizados, que engendra outro binômio: comunidade-ministérios (SCHILLEBEECK, 1965, p. 981-1000). Por isso, o Documento de Aparecida, retomando o Documento de Puebla, fala da Igreja como “comunhão e participação" (DAp 213), "casa e escola de comunhão" (DAp 158). Daí a necessidade, na obra da evangelização, da participação “dos leigos no discernimento, tomada de decisões, do planejamento e da execução”, (DAp 371) (Cf. ASCENJO GÁLVEZ, 2008, 270). O Instrumentum Laboris do Sínodo da Amazônia fala da necessidade de "superar toda forma de clericalismo para viver a fraternidade e o serviço como valores evangélicos, que animam a relação entre a autoridade e os membros da comunidade" (IL 119C).

b) A corresponsabilidade dos batizados, em uma lgreja toda ela ministerial. Segundo o Vaticano II, todo o Povo de Deus é um povo profético, sacerdotal e régio, que tem o batismo como fundamento de todos os demais ministérios. Por isso, urgem processos de tomada de decisões relativas à pastoral, que contemplem a participação de todos, na corresponsabilidade de todos os batizados na obra da evangelização (cf. SCHILLEBEECKX, 1983). Neste sentido, o Documento de Aparecida (DAp) destaca a necessidade de promover

comunidades eclesiais na região, hoje, são majoritariamente coordenadas por mulheres, a ordenação ao diaconato e ao presbiterato é uma necessidade premente e culturalmente madura. 
"o protagonismo dos leigos, em especial das mulheres", estas com ministérios e "efetiva presença nas esferas de planejamento e nos processos tomada de decisão" (DAp 458). É necessário, na América Latina, superar uma mentalidade machista, que ignora a novidade do cristianismo, que reconhece e proclama a "igual dignidade e responsabilidade da mulher em relação ao homem" (DAp 453). O Instrumentum Laboris do Sínodo da Amazônia chama a atenção que "as culturas amazônicas possuem um alto sentido de comunidade, igualdade e de solidariedade, por isso não aceita o clericalismo"; "os povos originários possuem uma rica tradição de organização social onde a autoridade é rotativa e com um profundo sentido de serviço" (IL 127).

A Conferência de Aparecida denunciou, na contramão da renovação do Vaticano II, a volta do clericalismo. Ele está respaldado na velha eclesiologia pré-conciliar, que concebia a Igreja como uma "comunidade desigual", composta de "duas categorias" de cristãos: o clero, o polo ativo, no qual reside toda iniciativa e poder de decisão e, os leigos, o polo passivo, ao qual cabe obedecer docilmente ao clero. O Vaticano II significou uma reviravolta na relação dos padres e bispos com os leigos. Com sua "volta às fontes" bíblicas e patrísticas, o Vaticano II resgatou o modelo de Igreja das comunidades cristãs primitivas. No seio delas, a exemplo do que Jesus queria, existia um único gênero de cristãos - o dos batizados. É de uma comunidade toda ela profética, sacerdotal e régia, de onde brotam todos os ministérios para o serviço da comunidade, inserida na sociedade, inclusive os ministérios ordenados.

Durante séculos na Igreja, como não havia separação ou distância entre os diferentes ministérios, não existiu o termo "leigo". A Igreja é concebida como a comunidade dos batizados e os ministros ordenados presidem uma assembleia toda ela profética, sacerdotal e régia. Mais que isso, os ministérios ordenados, além de saírem do seio da comunidade, eram ministérios colegiados, exercidos em equipe. $O$ episcopado monárquico só se tornou regra depois de séculos e, ainda assim, jamais imposto, sempre exercido com o beneplácito da comunidade.

O Vaticano II resgatou a concepção de que "a Igreja somos nós", isto é, todos os batizados. Para a Lumen Gentium, não há duas categorias de cristãos, mas um único gênero - os batizados, que conformam uma Igreja toda ela 
ministerial. Daí a passagem do binômio clero-leigos para o binômio comunidade-ministérios. Diz o Concílio que há uma radical igualdade, em dignidade, de todos os ministérios. Nesta perspectiva, a Conferência de Santo Domingo irá propor o protagonismo dos leigos na evangelização e a de Aparecida, o protagonismo das mulheres, escandalosamente ainda tão discriminadas na Igreja, como o Papa Francisco tem reconhecido e deseja mudar.

Assim, em sua relação com a Igreja, o leigo não pode ser definido como um "não clérigo", com uma identidade negativa. Partindo da concepção da Igreja como uma "comunidade de iguais", o leigo tem uma identidade positiva, numa Igreja toda ela ministerial, em decorrência do tríplice múnus que todo fiel recebe no batismo (LG 33). Consequentemente, a relação entre os membros da Igreja não é de superioridade ou inferioridade, mas de complementariedade, no serviço à causa do Reino de Deus. A identidade cristã se funda no Batismo, sobre o qual se assenta também o sacramento da Ordem. A Igreja é conformada por todos os batizados, no exercício da diversidade de ministérios derivados do Batismo, incluído o ministério hierárquico.

No resgate da teologia do laicato oriunda do Vaticano II, o Papa Francisco tem sido um crítico contundente da volta do clericalismo. Numa entrevista , afirmou que "o clericalismo não tem nada a ver com cristianismo. Quando tenho na minha frente um clericalista, instintivamente me transformo num anticlerical”. Adverte que "na maioria dos casos, o clericalismo é uma tentação muito atual; trata-se de uma cumplicidade viciosa: o padre clericaliza o leigo e, o leigo, Ihe pede o favor de o clericalizar, porque, no fundo, Ihe é mais cômodo". Para o Papa, “o fenômeno se explica, em grande parte, pela falta de maturidade e de liberdade cristã em parte do laicato" (apud BRIGHENTI, 2018).

Em sua visita ao Brasil por ocasião da Jornada Mundial da Juventude, falando aos Bispos do CELAM, o Papa Francisco pergunta: “nós, Pastores, Bispos e Presbíteros, temos consciência e convicção da missão dos fiéis leigos e Ihes damos a liberdade para irem discernindo, de acordo com o seu caminho de discípulos, a missão que o Senhor Ihes confia? Apoiamo-los e acompanhamos, superando qualquer tentação de manipulação ou indevida submissão? Estamos sempre abertos para nos deixarmos interpelar pela busca do bem da Igreja e pela sua missão no mundo?" (PAPA FRANCISCO, Discursos 
$J M J, 2013)$. Como real espaço do exercício da corresponsabilidade de todos os batizados na Igreja, o Papa recorda aos Bispos a importância dos conselhos: "os Conselhos paroquiais de Pastoral e de Assuntos Econômicos têm sido espaços reais para a participação laical na consulta, organização e planejamento pastoral? O bom funcionamento dos Conselhos é determinante. Acho que estamos muito atrasados nisso" (PAPA FRANCISCO, Discursos $J M J, 2013)$.

Uma Igreja toda ela ministerial é uma Igreja atuante no âmbito eclesial, mas como a missão da Igreja é no mundo e para ser mediação da salvação de Jesus Cristo no mundo, é preciso criar ministérios para o serviço no mundo. É missão de todo cristão um estreito compromisso na sociedade, para tornar presente nela o Reino de Deus. A Constituição Gaudium et Spes é clara: "a esperança de uma Nova-terra, longe de atenuar, antes deve impulsionar a solicitude pelo aperfeiçoamento desta terra" (GS 39). E continua: "afastam-se da verdade os que sabendo não termos aqui morada permanente, mas buscarmos a futura julgam, por conseguinte, poderem negligenciar os seus deveres terrestres, sem perceberem que estão mais obrigados a cumpri-los, por causa da própria fé, de acordo com a vocação à qual cada um foi chamado" (GS 43). E adverte: "não erram menos aqueles que, ao contrário, pensam que podem entregar-se de tal maneira às atividades terrestres, como se elas fossem absolutamente alheias à vida religiosa, julgando que esta consiste somente em atos de culto e ao cumprimento de alguns deveres morais. Este divórcio entre fé professada e a vida cotidiana de muitos deve ser enumerado entre os erros mais graves de nosso tempo" (ibid). E conclui: "ao negligenciar os seus deveres temporais, o cristão negligencia os seus deveres para com o próximo e o próprio Deus e coloca em perigo a sua salvação eterna" (ibid.).

\section{$4^{\circ}$ Desafio: Participação e protagonismo das mulheres na Igreja}

Para Aparecida, uma Igreja toda ela ministerial, na corresponsabilidade de todos, implica, impulsionar uma organização pastoral que promova o protagonismo das mulheres e garanta a efetiva presença da mulher nos ministérios, assim como nas esferas de planejamento e decisão (DAp, 458). 
Pois, inumeráveis mulheres, de toda condição social, não são valorizadas em sua dignidade e heroica generosidade no cuidado e educação dos filhos, nem na construção de uma vida social mais humana e na edificação da Igreja. É necessário, na América Latina, superar uma mentalidade machista, que ignora a novidade do cristianismo, que reconhece e proclama a "igual dignidade e responsabilidade da mulher em relação ao homem" (DAp, 453).

$\mathrm{Na}$ superação do clericalismo, em vista de uma Igreja toda ela ministerial, o Papa Francisco também alude ao lugar e ao papel das mulheres. Falando aos Bispos do CELAM no Rio de Janeiro, adverte: "não reduzamos o empenho das mulheres na Igreja; antes, pelo contrário, promovamos o seu papel ativo na comunidade eclesial. Se a Igreja perde as mulheres, na sua dimensão global e real, ela corre o risco da esterilidade”. Na Exortação Evangelii Gaudium, diz que reconhece, “com alegria, como muitas mulheres partilham responsabilidades pastorais com os presbíteros, contribuem para acompanhamento de pessoas, de famílias e grupos, assim como enriquecem a reflexão teológica. Entretanto, é necessário ampliar os espaços para uma presença feminina mais incisiva na Igreja" (EG 103).

Superar o clericalismo, em relação às mulheres, equivale à Igreja se despatriarcalizar. E a uma Igreja despatriarcalizada corresponde uma Igreja com ministérios instituídos para as mulheres. A abertura do Papa Francisco à pesquisa sobre a presença de diaconisas na Igreja antiga sinaliza que passos precisam ser dados, sem muito mais esperar. Nada impede que, no seio das comunidades eclesiais, um pouco do muito que virá já possa ser começado. Não se pode esquecer que o Vaticano II começou antes do Vaticano II e que muitas de suas decisões foram antes transgressões do Espírito, que sopra onde e quando quer, como soprou nas iniciativas dos grupos que o prepararam.

O sopro do Espírito inicia em Maria, a palavra eterna que se exprime na criação e comunica-se na história da salvação, se tornou em Cristo um homem, "nascido de mulher" (Gl 4,4). Inspiradas pelo esse sopro, ao longo da história da Igreja, muitas mulheres se destacaram por terem colocado esse sopro em prática em contextos diversos, também no contexto da Amazônia. Mulheres que saíram de si e foram ao encontro dos necessitados, cumprindo o projeto de Deus - o cuidado da Casa Comum e dos que habitam esta casa. 
O rosto da Igreja na Amazônia é um rosto misericordioso, marcado pelo rosto feminino de Deus. Muitas de suas mulheres derramaram o seu sangue, defendendo a vida das pessoas e dos ecossistemas. A participação das mulheres na evangelização, segundo as necessidades dos contextos da Amazônia, fazem-nos ouvir alguns clamores silenciosos, mas urgentes para as mudanças estruturais da Igreja. Urge uma Igreja, toda a ela ministerial, empenhada em ampliar, consolidar e consagrar a diversidade dos ministérios e o papel das mulheres, com atenção especial ao clamor pela presença da Eucaristia nas comunidades eclesiais, como direito de todo o Povo de Deus.

\section{$5^{\circ}$ Desafio: Os contextos urbanos na Amazônia - desafios e urgências para uma Igreja em saída}

O atual processo de urbanização na Amazônia converteu-se em um dos desafios mais importantes para a ação evangelizadora e missionária da Igreja em saída. O fenômeno urbano e sua complexidade se dá em termos de migração e de aglomeração nas grandes cidades, e também em termos de cultura globalizada que atinge também as comunidades rurais e mesmo as aldeias dos povos indígenas, com estilos de vida e modos de convivência, linguagens e valores, subjetividade e massificação, secularização e busca do transcendente.

Por isso, na Amazônia, interior e cidade não podem ser pensados como realidades desconectadas ou separadas. Por um lado, é necessário uma compreensão maior dos mecanismos que levaram a um crescimento desmedido dos núcleos urbanos e a um esvaziamento do interior, porque ambas dinâmicas fazem parte de um mesmo sistema um modelo econômico que avança sobre os territórios para apropriar-se deles e colocá-los à serviço do capital precisa do esvaziamento do interior e do despejo das comunidades, que muitas das vezes terminam migrando para as cidades e acabam nas periferias urbanas sem que seus direitos fundamentais sejam garantidos.. Assim, é necessário consolidar políticas públicas e iniciativas de fomento à qualidade de vida interior, para combater o descontrolado êxodo rural. Por outro lado, o horizonte urbano constitui uma espécie de "porta de entrada" para compreender todo o processo da globalização e seus efeitos. O desafio 
principal é como promover um padrão de desenvolvimento que concilie a produção com o cuidado da casa comum, a integridade e o bem-estar de seus habitantes. As cidades são condições-chave para viabilizá-lo. Ciência e tecnologia podem e devem contribuir para vencer o desafio da utilização social e econômica sustentável do patrimônio natural e cultural da Amazônia em benefício das populações regionais, do país e do planeta.

Como se situa a Igreja diante destes desafios e de que maneira poderia articular melhor sua presença e sua ação? A perspectiva da "conversão pastoral" (DAp 365, 366, 368, 370) pode vir ao nosso encontro desdobrando-se em 8 dimensões essenciais e interconexas do fenômeno urbano, correspondentes às suas respectivas tarefas eclesiais:

a) Dimensão teologal. Compreender profundamente, com um olhar de fé, que "Deus vive na cidade" (DAp 514) e nos convida a participar de sua missão enxergando, na ambivalência dos "sinais dos tempos", os caminhos de vigilância profética e de edificação do Reino. Algo na cidade está acontecendo em direção à realização do projeto de Deus.

b) Dimensão sociológica. É necessário conhecer analiticamente o contexto urbano através de uma abertura interdisciplinar como mediação fundamental para poder responder aos desafios urbanos de hoje. Impõe-se uma atitude dialogal positiva junto aos interlocutores que vivem nas urbes, para construir juntos uma sociedade justa e fraterna.

c) Dimensão cultural. Assumir o contexto plural no qual hoje se move a humanidade, com uma atitude de desprendimento, atenção e abertura em relação às diferentes expressões culturais presentes no contexto urbano, com uma avassaladora presença da mídia e cada vez mais das redes digitais. Isso implica uma ação eclesial e missionária diversificada, que rechace decididamente toda forma de integralismo ideológico e de intolerância religiosa.

d) Dimensão política. Estruturas de poder estão sempre mais sujeitas a interesses macroeconômicos, acobertados por uma ideologia sedutora e uma propaganda moralista ou destituída de qualquer referência a valores, centrada apenas na exacerbação do individualismo e do consumismo. Práticas pastorais que surgem nos interstícios dos contextos urbanos, resgatam valores, expressões e cosmovisões subalternas, em defesa dos direitos humanos, 
na promoção de políticas públicas e de uma consciência verdadeiramente democrática.

e) Dimensão cristológica. "O encontro com Jesus Cristo através dos pobres é uma dimensão constitutiva de nossa fé em Jesus Cristo" (DAp 257). Uma autêntica conversão pastoral implica sempre oferecer com "toda a imaginação da caridade" (DAp 176) uma "atenção especial ao mundo do sofrimento urbano, isto é, que cuide dos caídos ao longo do caminho e aos que se encontram nos hospitais, encarcerados, excluídos, dependentes das drogas, habitantes das novas periferias, nas novas urbanizações e das famílias que, desintegradas, convivem de fato" (DAp 517j).

f) Dimensão ecológica. Diante da degradação ambiental urbana, que causa por sua vez uma degradação humana, é indispensável promover uma ecologia integral a partir do cuidado com o ambiente no qual se vive e se trabalha: "Não há duas crises separadas: uma ambiental e outra social; mas uma única e complexa crise socioambiental" (LS 139).

g) Dimensão eclesial. Cuidar de espaços e estruturas urbanas implica também uma conversão dos espaços e das estruturas eclesiais mais cônsonas às dinâmicas urbanas. Junto aos templos de portas abertas para todos, como lugares de oração e celebração, de realização de encontros e assembleias, é imprescindível promover a criação, a experiência e a articulação de comunidades eclesiais, para que a paróquia se torne uma comunidade de comunidades (DAp 172).

h) Dimensão missionária. Não é suficiente que a Igreja se torne um lugar de acolhida das pessoas por meio de seus espaços e de suas estruturas. É preciso que a Igreja e seus agentes se façam próximos das comunidades mais longínquas, através de um dinamismo de saída e de encontro. A Missão da Igreja é muito mais do que acolher: é se dispor a ser acolhidos pelos outros.

\section{$6^{\circ}$ Desafio: Formação teológico-política do clero e do laicato na Amazônia}

Para uma Igreja missionária em saída, a qualificação de seus agentes é um fator altamente determinante, exatamente porque aponta para a inculturação, a participação e a transformação da sociedade: "os melhores 
esforços das paróquias neste início do terceiro milêniodevem estar na convocação e na formação de leigos missionários" (DAp 174). O Documento de Aparecida fala de uma "clara e decidida opção pela formação dos membros de nossas comunidades" (DAp 276), que deverá ser bíblico-teológica, abrangente, inculturada, continuada e que possa integrar as dimensões humana, relacional, espiritual, intelectual e pastoral-missionária.

a) Formação bíblico-teológica. Papa Francisco na Evangelii Gaudium fala exaustivamente de uma catequese querigmática (EG 160-175; DAp 279), que evita ser primariamente doutrinária (EG 161; DAp 299) e moralista (EG 165). Essa dimensão é baseada no primeiro anúncio e na Palavra de Deus, núcleo essencial, profético e afetivo do Evangelho, que devemos continuamente assimilar, ressignificar e comunicar para interiorizá-lo e experienciá-lo em nossa vida. O primeiro anúncio é “o anúncio principal, aquele que sempre se tem de voltar a ouvir de diferentes maneiras e aquele que sempre se tem de voltar a anunciar, duma forma ou doutra, durante a catequese, em todas as suas etapas e momento" (EG 164).

b) Formação abrangente. A tradição missionária da Igreja sempre incentivou a preparação esmerada de seus agentes nas mais diversas áreas do conhecimento, particularmente, antropológico, linguístico, étnico e religioso (AG 34), não somente para o clero e os religiosos, mas também e, sobretudo, para os leigos e as leigas, pois "sem a presença ativa dos leigos, o Evangelho não pode gravar-se profundamente nos espíritos, na vida e no trabalho de um povo" (AG 21). Um enfoque especial merece a formação no âmbito político e da doutrina social da Igreja para todos os setores eclesiais, em vista do exercício da cidadania, do bem comum e da promoção de políticas públicas (DAp 99f; 505). Com efeito, "esquece-se de que a democracia e a participação política são fruto da formação que se faz realidade somente quando os cidadãos são conscientes de seus direitos fundamentais e de seus deveres correspondentes" (DAp 77).

c) Formação inculturada. Engendra não somente o respeito para o jeito próprio de cada cultura, particularmente na formação presbiteral (DAp 325), mas também o processo de aprendizagem da Igreja missionária com as expressões do cotidiano de cada povo e com suas riquezas espirituais. Não há caminho mais válido do que a fé inculturada, que encontra seus próprios meios 
de expressão e que revela a personalidade de cada grupo humano, sua própria experiência de fé. Não pode de forma alguma a catequese e formação teológico-pastoral propor-se como estrangeira e ocidentalizada, impondo como condição às pessoas que vivem na Amazônia que deixem de ser elas próprias para viver uma fé com moldes culturais exógenos (já a Maximum Illud de Bento XV, da qual celebramos os 100 anos, lembrava desse princípio). Um elemento essencial nesta dimensão da inculturação é a aprendizagem da língua dos diversos povos: "torna-se necessário aprender a língua da região onde trabalham [os missionários], conhecer as expressões mais significativas da sua cultura, descobrindo os seus valores por experiência direta. Eles só poderão levar aos povos, de maneira crível e frutuosa, o conhecimento do mistério escondido, através daquela aprendizagem" (RMi 53 ).

d) Formação continuada. A condição permanente de discípulos missionários exige uma atitude constante de aprendizagem, um contínuo aprender a aprender. Uma formação continuada, proposta com modalidades e tempos adequados, "de acordo com o desenvolvimento das pessoas e como serviço que são chamadas a prestar, em meio às exigências da história” (DAp 279), é requisito necessário para acompanhar as rápidas transformações das nossas sociedades e do ambiente no qual vivemos. Enfrentar os desafios proporcionados pela complexidade global e suas causas exige, também, uma abordagem multidisciplinar e intercultural, que requerem por sua vez uma mente aberta e articulada sobre as diferentes maneiras de enxergar a realidade (LS 63).

e) Formação integrada. Não basta uma formação em termos teóricos e escolásticos. Apontar para uma formação integral significa considerar o desenvolvimento de todas as dimensões do ser humano, psíquicas, relacionais, intelectuais, espirituais e operativas (PDV 43-59; DAp 518d). Por isso, escolas de formação e seminários inseridos numa realidade comunitária e sociocultural são ambientes e perspectivas indispensáveis para a formação de agentes de pastorais aptos para os diversos serviços missionários (DAp 322). Clericalismo, autoritarismo, integralismo são atitudes frequentes detectadas pelo povo no clero mais jovem, como também em militâncias de alguns movimentos eclesiais, que revelam insegurança, imaturidade e fuga da realidade. Papa Francisco afirma com decisão: "o clericalismo, que não é apenas dos clérigos, 
é uma atitude que concerne todos nós: o clericalismo é uma perversão da Igreja" (Encontro do Papa Francisco com os jovens italianos em vista do Sínodo, Roma, 11 de agosto de 2018).

\section{Desafio: A comunicação desde a Amazônia}

É fato que a informação veiculada pela grande mídia está a serviço dos interesses macroeconômicos, da manutenção do status quo capitalista desigual, da consolidação de estruturas injustas de manipulação das massas e da exploração de recursos humanos e naturais. Há tempo, os donos do poder não recorrem mais à violência física para subjugar as diversas camadas da sociedade, e sim a uma violência simbólica, a uma narrativa complacente e insistente, a uma semântica colonial de sedução que convence as pessoas de que dominação, acumulação e privilégios são promovidas para o bem de todos: "não há dominação de poucos sobre muitos sem o recurso à mentira e ao engano" (SOUZA, 2018, p. 58)

A íntima relação entre poder econômico e poder midiático é estrutural e institucional numa sociedade profundamente desigual. A informação independente e seu prestígio na coletividade é uma conquista democrática de comunidades que atingiram um patamar razoável de igualdade, justiça e participação. Ao contrário, num mundo profundamente dominado, hierarquizado e fragmentado, até as redes sociais, intrinsecamente abertas e interativas, se tornaram alvos de ataques cibernéticos e de fake news, quando não, e sobretudo, instrumentos totalitários de controle social.

Diante deste cenário de complexidade do contexto atual, o Documento de Aparecida enfatiza que "qualquer pessoa individual necessita sempre mais informação, se deseja exercer sobre a realidade o senhorio a que, por vocação, está chamada" (DAp 36). Por isso a Igreja necessita "otimizar o uso dos meios de comunicação católicos, fazendo-os mais atuantes e eficazes, seja para a comunicação da fé, seja para o diálogo entre a Igreja e a sociedade" (DAp 497b). Necessita também de comunicadores conscientes e bem preparados que atuem nos diferentes meios seculares: na imprensa, no rádio, na TV, nas redes sociais, nos sites e nos blogs. 
Desde a Redemptoris Missio, um grande destaque é dado ao mundo das comunicações como relevância fundamental para a missão da Igreja (RMi 37c). Com efeito, o grande areópago de hoje é a sociedade em rede em nível planetário, sustentada pelas novas tecnologias. A internet e as redes sociais passam a ser parte integrante da vida cotidiana. Tornar-se presente no ambiente digital é fazer do próprio tecido da sociedade um âmbito privilegiado de atuação: aqui os cristãos são chamados a exercer uma "diaconia da cultura" (BENTO XVI. Mensagem para o 44 Dia Mundial das Comunicações Sociais, 2010), buscando também novas modalidades de participação política (PONTIFÍCIA COMISSÃO PARA A AMÉRICA LATINA. O indispensável compromisso dos leigos na vida pública dos países latino-americanos, 2016, p. 38).

Para a ação evangelizadora e transformadora da Igreja na Amazônia é estratégico pensar e articular um plano de comunicação a partir das comunidades locais, que são presença capilar no território. Só é possível sustentar uma presença e uma atuação profética da Igreja na Amazônia se esta contar com uma rede de comunidades autóctones e autônomas. Um modelo de Igreja descentralizada, participativa e sinodal, encarnada num contexto de amplas dimensões geográficas com poucas vias físicas de acesso, necessita de meios que garantam uma articulação eficaz e uma comunhão verdadeira.

Junto à procura por soluções técnicas, vistas as enormes dificuldades de muitas regiões amazônicas de ter acesso às redes de comunicação, torna-se necessário articular e somar forças com o que já existe, buscando aprimorar esforços, qualificar competências, abrir caminhos autossustentáveis e formar agentes, assim como a consciência crítica e o discernimento dos cristãos na sociedade. As missionárias e os missionários são comunicadores por excelência, chamados a "primeirear", a tomar iniciativa sem medo, a ir à frente (EG 24), a ter a ousadia de empreender processos de proximidade e encontro com as pessoas, pois a comunicação jamais pode ser vista como transmissão, deslocamento, transferência, mas como interação e diálogo com as diversas realidades.

Desenvolver uma política e um projeto de comunicação social não é apenas uma questão de planejamento institucional que visa dominar linguagens midiáticas, buscar recursos necessários ou aprender a melhor utilizar os meios. Para a ação evangelizadora da Igreja contam particularmente 
os conteúdos da comunicação, os pensadores e os formadores de opinião (DAp 492; 497d), o aprofundamento das questões, a elaboração de perguntas significativas numa perspectiva de libertação integral das pessoas, da sociedade e da casa comum no seu conjunto. O Evangelho é chamado continuamente a redescobrir e atualizar sua dimensão profética, pois o poder transformador da Palavra se expressa na sua efetiva e concreta relevância para uma sociedade humana e seus interlocutores (DAp 517h).

As boas mensagens compartilhadas e bem veiculadas podem ter um impacto transformador na vida das pessoas. Da mesma forma, o Evangelho encarnado e compartilhado: “A Palavra possui, em si mesma, uma tal potencialidade, que não a podemos prever. O Evangelho fala da semente que, uma vez lançada à terra, cresce por si mesma, inclusive quando o agricultor dorme (cf. Mc 4,26-29). A Igreja deve aceitar esta liberdade incontrolável da Palavra, que é eficaz a seu modo e sob formas tão variadas que muitas vezes nos escapam, superando as nossas previsões e quebrando os nossos esquemas" (EG 22).

\section{Considerações finais}

Para uma evangelização consequente com o contexto amazônico, as Igrejas Locais da Região precisam fazer de seu Sínodo um passo importante na configuração de Igrejas autóctones, expressão de uma eclesiologia pluriforme, conforme o modelo neotestamentário. É a hora de ousar, pois, apesar da abertura do novo pontificado, juridicamente, continua a milenar centralização que impede de responder com mais agilidade e propriedade aos desafios oriundos de contextos particulares. Fundado na legitimidade do exercício da sinodalidade eclesial entre as Igrejas Locais e a Igreja de Roma, o Sínodo precisa ser expressão da autonomia necessária para tomar decisões diante de certas demandas que não podem esperar.

Sem a necessária autonomia, um rosto próprio fruto da inculturação da fé no contexto amazônico segundo o perfil da tradição eclesial libertadora tecida em torno à Conferência de Medellín continuará mais desejo do que realidade ou mesmo "brasas sob cinzas" de um largo processo de involução eclesial (GONZÁLEZ FAUS, 1989, p. 67-84). É hora de passar da resistência à 
ousadia de avançar, da repetição de modelos de Igreja esclerosados à criatividade sob o dinamismo do Espírito. Tarefas concretas, como uma liturgia que incorpore no rito a cultura dos povos da Região, uma teologia própria como a teologia índia, ministérios configurados segundo as condições e necessidades locais, enfim, uma pastoral de conversão missionária que faça das periferias o centro da Igreja, precisam fazer parte da agenda do Sínodo.

Por isso, como diz a Conferência de Aparecida, só a conversão pastoral da Igreja como um todo pode levar a retomar a renovação do Vaticano II e a tradição eclesial libertadora da Igreja na América Latina no novo contexto em que vivemos, de onde brota a necessidade de uma Igreja com rosto amazônico. É uma tarefa imensa e complexa, pois implica conversão na autoconsciência da Igreja, nas ações, nas relações de autoridade e nas estruturas, sob o protagonismo do Espírito. Tarefa imensa e complexa, mas não impossível se nossa Igreja conseguir "desinstalar-se de seu comodismo, estancamento e tibieza, à margem do sofrimento dos pobres do Continente". Para isso, dizem os bispos, "esperamos um novo Pentecostes que nos liberte do cansaço, da desilusão e da acomodação em que nos encontramos" (DAp 362).

\section{Referências}

AMERINDIA. Hacia el Sínodo Panamazónico. Desafíos y aportes desde América Latina y el Caribe. DGP Editores: Bogotá, 2019.

APARECIDO DA SILVA, A. "Théologie afro-américaine au Brésil: expression du pluralisme théologique ». Em: MULLER, H. A. M.; VILLEPELET, D. Risquer la foi dans nos sociétés. Églises d'Amérique latine et d'Europe en dialogue. Paris: Karthala, 2005. p. 183-197.

ARAUJO, W. TAVEIRA, B e FOGAÇA, T. Geografia da população. Curitiba: Intersaberes, 2016.

ASCENJO GÁLVEZ, L. A. "La conversión pastoral: un llamado a vivir en libertad y comunión”. Medellín 134 (2008): 247-275.

BEOZZO, J. O. «Globalisation en Amérique latine dans le contexte historique des interactions mondiales ». Em: MULLER, H. A. M.; VILLEPELET, D. Risquer la foi dans nos sociétés. Églises d'Amérique latine et d'Europe en dialogue. Paris: Karthala, 2005. p. 85-116. 


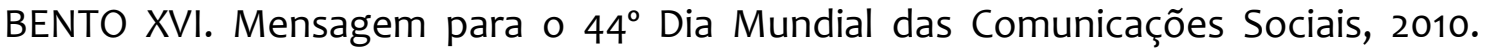
Disponível em: <http://www.vatican.va/content/benedict-xvi/pt/messages/comm unications/documents/hf_ben-xvi_mes_20100124_44th-world-communicationsday.html>. Acesso em: 30 de Jul. 2019.

BRIGHENTI, A. Por uma evangelização inculturada. Princípios pedagógicos e passos metodológicos. São Paulo: Paulinas, 1998, p. 10-23.

BRIGHENTI, A. "A pastoral na vida da Igreja. Repensando a missão evangelizadora em tempos de mudança". CNBB-Comissão episcopal para a Animação Bíblico-catequética. Congresso Nacional de Catequese. Brasília: Ed. CNBB: 2012. p. 117-138.

BRIGHENTI, A. "Énfasis pastorales de la Iglesia en América Latina y El Caribe en los últimos 50 años". Revista Medellín, n. 123, p. 375-398, 2005.

BRIGHENTI, A. Dívida Externa e Neocolonialismo. Por uma globalização da Solidariedade. São Paulo: Paulinas, 2002.

BRIGHENTI, A. A situação do laicto segundo Aparecida e o Papa Francisco. Disponível em: $\quad$ http://www.amerindiaenlared.org/contenido/13768/a-situacao-do-laicadosegundo-aparecida-e-o-papa-francisco-o-laicato-na-igreja-e-no-mundo-3/>. Acesso em: 08 dez. 2018.

CADAVID, A. "El camino pastoral de la Iglesia en América Latina y el Caribe". Revista Medellín, n. 123, p. 331-374, 2005.

CONCÍLIO VATICANO II. Constituição dogmática Lumen gentium [LG]. In: Compêndio do Vaticano II. $22^{\text {a }}$ ed. Petrópolis: Vozes, 1991, p. 37-117.

CONCÍLIO VATICANO II. Decreto Ad gentes [AG]. In: Compêndio do Vaticano II. $22^{\text {a }}$ ed. Petrópolis: Vozes, 1991, p. 351-399.

CONCÍLIO VATICANO II. Constituição pastoral Gaudium et spes [GS]. In: Compêndio do Vaticano II. $22^{\text {a }}$ ed. Petrópolis: Vozes, 1991, p. 141-256.

CONSELHO EPISCOPAL LATINO-AMERICANO. Documento de Santo Domingo [DSD]. <http://portal.pucminas.br/imagedb/documento/DOC_DSC_NOME_ARQUI20130906 182510.pdf >. Acesso em: 28 jul. 2019.

CONSELHO EPISCOPAL LATINO-AMERICANO. Documento de Aparecida: Texto conclusivo da V Conferência Geral do Episcopado latino-Americano e do Caribe [DAp]. São Paulo: Paulinas, 2007.

CNBB. Cristãos leigos e leigas na lgreja e na sociedade, documento 105, Brasília, 2017.

CNBB. Campanha da Fraternidade 2007: Fraternidade e Amazônia, Brasília, 2007.

FERREIRA, R. “Uma Igreja com rosto amazônico”. Vida Pastoral, n. 327, p. 23-34, 2019. 
FRANÇA MIRANDA, M. de. Inculturação da Fé. Uma abordagem teológica. São Paulo: Loyola, 2001.

GONZÁLEZ FAUS, J. I. “El meollo de la involución eclesial”. Revista Razón y Fe, v. 220, n. $1089 / 90$, p. $67-84,1989$.

GUTIÉRREZ, G. “La recepción del Vaticano II en América Latina”. Em G. Alberigo y J.P. Jossua (eds.). La recepción del Vaticano II. Madrid: Cristiandad, 1987, 213-237

KELLER, M. A. "A Conferência de Puebla: contexto, preparação, realização, conclusões, recepção". Em:BRIGHENTI, A.;PASSOS, J. D. Compêndio das Conferências dos Bispos da América Latina e Caribe. São Paulo: Paulinas-Paulus, 2017. p. 83-93.

LEGRAND, H. La réalisation de l'Église en un lieu. Initiation à la pratique de la théologie III. Paris: Cerf, 1993.

LOBINGER, F. Padres para amanhã: proposta para comunidades sem eucaristia. São Paulo: Paulus, 2007.

LUNEAU, R.; LADRIÈRE, P. Le retour des certitudes. Paris: Centurion, 1987.

LUNEAU, R.; LADRIÈRE, P. Le rêve de Compostelle. Paris: Centurion, 1990.

NANDI, D.V. Os temas ecológicos nas Campanhas da Fraternidade. Revista Encontros Teológigos n. 3, 2015, Florianópolis, p. 27-36, Disponível em: <https://facasc.emnuvens.com.br/ret/article/viewFile/27/23>. Acesso em: 06 Jun. 2019.

PALOSCHI, R. "O Sínodo da Amazônia: grito à consciência, memória da missão, opção pela vida”. Vida Pastoral, n. 327, p. 15-22, 2019.

PAPA FRANCISCO. Discursos JMJ 2013. Disponível em: <http://www.vatican.va/content/francesco/pt/speeches/2013/july/documents/papafrancesco_20130728_gmg-celam-rio.html>. Acesso em: 03 jul. 2019.

PAPA FRANCISCO. Exortação Apostólica Evangelii Gaudium: a Alegria do Evangelho [EG]. São Pauo: Paulinas. 2013.

PAPA FRANCISCO. Carta Encíclica Laudato Si': sobre o cuidado da casa comum [LS]. São Paulo: Paulinas, 2015.

PAPA JOÃO PAULO II. Carta encíclica Redemptoris missio [RMi]. Disponível em: <http://www.vatican.va/content/john-paul-ii/pt/encyclicals/documents/hf_jpii_enc_07121990_redemptoris-missio.html>. Acesso em: 28 jul. 2019.

PAPA JOÃO PAULO II. Exortação apostólica pós-sinodal Pastores dabo vobis [PDV]. Disponível em: <http://www.vatican.va/content/john-paul-ii/pt/apost_exhortations/ documents/hf_jp-ii_exh_25031992_pastores-dabo-vobis.html>. Acesso em: 28 jul. 2019. 
PONTIFÍCIA COMISSÃO PARA A AMÉRICA LATINA. O indispensável compromisso dos leigos na vida pública dos países latino-americanos. São Paulo: Paulinas, 2016.

ROCA ALCAZAR, F. El Sínodo amazónico, la Amazonía y la Iglesia. Perspect. Teol., Belo Horizonte, v. 51, n. 1, p. 55-67, jan/abr.2019.

SCATENA, S. In populo pauperum. La chiesa latinoamericana dal Concilio a Medellín (1962-1968). Bologna: II Molino, 2007.

SCHILLEBEECKX, E. El ministerio eclesial: Responsables en la comunidad cristiana. Madrid: Cristiandad, 1983.

SECRETARÍA DEL SÍNODO DE LOS OBISPOS. Amazonía: nuevos caminos para la lglesia y para una ecología integral. Lineamenta. Bollettino, Sala Stampa della Santa Sede, Roma: Oficina de Prensa de la Santa Sede, 08/06/2018.

SECRETARIA GERAL DO SÍNODO. Amazônia: novos caminhos para a Igreja e para uma ecologia integral. Instrumentum Laboris. Libreria Editrice Vaticana, Roma, 2019.

SOBRINO, J. "El Vaticano Il y la Iglesia latinoamericana". Em FLORISTÁN, C.; TAMAYO, J.-J. (eds.), El Vaticano II, veinte años después. Madrid: Cristiandad, 1985, 105-134.

SOUZA, J. A classe média no espelho. Rio de Janeiro: Estação Brasil, 2018.

TILLARD, J. M. R. Église d'Églises. L'écclesiologie de communion. Paris: Les Éditions du Cerf, 1987. 